\title{
Chemical Treatment to Recover Molybdenum and Vanadium from Spent Heavy Gasoil Hydrodesulfurization Catalyst
}

\author{
Alma Delia Rojas-Rodríguez ${ }^{1}$, Orlando Flores-Fajardo², Fabiola Selene Alcántar González², \\ Néstor Noé López Castillo², Modesto Javier Cruz Gómez ${ }^{2}$ \\ ${ }^{1}$ Faculty of Engineering, Universidad Anáhuac México Norte, México City, México \\ ${ }^{2}$ Chemical Engineering Department of the Faculty of Chemistry, Universidad Nacional Autónoma de México (UNAM), \\ Coyoacán, México \\ Email: mjcg@unam.mx
}

Received January 28, 2012; revised February 29, 2012; accepted March 10, 2012

\begin{abstract}
Large quantities of spent hydrodesulfurization (HDS) catalysts are available from petrochemical industry. Disposal of spent catalyst is a problem as it falls under the category of hazardous industrial waste due to its vanadium concentration. Most of these catalysts are usually supported on alumina containing a variable percentage of elements such as nickel or molybdenum. Hence these catalysts contain environmentally critical, and economically valuable metals such as molybdenum, vanadium, and, nickel. In this paper, a spent HDS catalyst was treated with caustic soda solution. Parameters such as temperature, time, and $\mathrm{NaOH}$ solution concentration have been studied thoroughly, in order to settle the appropriate conditions for the maximum recovery of molybdenum and vanadium. Under the best leaching conditions (20\% $\mathrm{w}$ $\mathrm{NaOH}$, room temperature, $2 \mathrm{~h}$ ) about $95 \%$ recovery of Mo and $\mathrm{V}$ was achieved, and the recovery of nickel obtained was of $99 \%$ in the form of $\mathrm{NiAlO}_{4}$.
\end{abstract}

Keywords: Spent HDS Catalyst; Vanadium; Molybdenum; Metal Recovery

\section{Introduction}

Metals like Ni, Mo, Co, Rh, Pt, Pd, etc., are widely used as catalysts in chemical and petrochemical industries [1]. They are generally supported on porous materials like alumina and silica through precipitation or impregnation processes. In many cases, metals are founded as oxides; however, they can also be reduced into active metals for catalyzing the appropriate reactions.

After a periodical use of the catalysts, due to the poisoning effect of foreign materials and impurities which deposit on the surface of the catalyst, they will become inactive [2]. Therefore fresh catalysts must be used, and the spent catalyst will be discarded as waste material.

Disposal of such catalyst materials, which contain appreciable amounts of heavy metals, is environmentally hazardous. On this account, a suitable and economically viable method for the recovery of metal, that should not pose the risk of environmental jeopardies, is required. Hence the recovery of nickel, molybdenum, and vanadium from such catalysts has attracted the attention of several investigators.

A representative sample, from a typical gasoil hydro- desulfurization unit at the PEMEX (Petróleos Mexicanos) Refineries, was used in the present study. The caustic soda method has been investigated and optimized for recovering soluble molybdate and vanadate from spent catalyst from HDS process. The objective of this research was to determine the spent catalyst composition and the process conditions (caustic soda and hydrochloric acid concentrations, temperature and time reaction).

It is known that each refining company uses different catalysts with its own composition. Therefore, the recovery methods should be adjusted to the industrial conditions and problems from each company. Various processes have already been developed.

K. Inoue et al. [3] studied a spent $\mathrm{Co}-\mathrm{Mo} / \mathrm{Al}_{2} \mathrm{O}_{3}$ catalyst deposited mainly with $\mathrm{V}$ and $\mathrm{Ni}$ from its operation. The catalyst was roasted at $973 \mathrm{~K}$, suspended in 63\% $\mathrm{H}_{2} \mathrm{SO}_{4}$, and evaporated up to dryness. Subsequently, it was dissolved in water and filtered to remove small amounts of silica. The filtrate was diluted to reach a $\mathrm{pH}$ of 1.2; this solution was extracted by a series of comercial extracting agents. The separation of $\mathrm{Co}$ and $\mathrm{Ni}$ from $\mathrm{Al}$ can be achieved but the procedure may be too expensive. 
The invention patented by Van Deelen [4] involves roasting the spent catalyst in an oxidizing environment at $1273-1473 \mathrm{~K}$ for 0.5 to $3 \mathrm{~h}$, in order to convert $\gamma-\mathrm{Al}_{2} \mathrm{O}_{3}$ to $\alpha-\mathrm{Al}_{2} \mathrm{O}_{3}$. Afterwards, metals such as $\mathrm{Mo}, \mathrm{W}, \mathrm{Ni}, \mathrm{Co}$, and $\mathrm{V}$ are solubilized from the roast using an acid medium at $\mathrm{pH}$ of 1 - 2. The final recovery of metals from the solution can be accomplished by solvent extraction.

In the study published by J. Mining et al. [5], sodium containing agents such as $\mathrm{Na}_{2} \mathrm{CO}_{3}$, was roasted with a spent HDS catalyst at $1123 \mathrm{~K}$. The roasted products were dissolved into hot water. The extraction of Mo and $\mathrm{V}$ approached $96 \%$. However, incomplete oxidation of the catalyst during roasting affected the extraction.

Biswas et al. [6] used $\mathrm{NaCl}+\mathrm{H}_{2} \mathrm{O}$ vapor to roast the decoked Co- $\mathrm{Mo} / \mathrm{Al}_{2} \mathrm{O}_{3}$ catalyst used in a heavy oil upgrading. After $2 \mathrm{~h}$ of roasting at $1123 \mathrm{~K}$ the catalyst was leached with water at $373 \mathrm{~K}$. The results showed that more than $80 \%$ of the $\mathrm{V}$ and Mo could be leached out at $373 \mathrm{~K}$. Most of the $\mathrm{V}$ was precipitated from the leachate using $\left(\mathrm{NH}_{4}\right)_{2} \mathrm{SO}_{4}$ at $\mathrm{pH}$ 8.6.

The CRI-MET two stage process was described in detail by Goerlich et al. [7]. In this process, the spent catalyst is pulverized and the Mo and V are solubilized, the sulphur is converted to sulphates, and the coke is partially oxidized by wet air oxidation. In the second stage, the alumina is solubilized as sodium aluminate together with the remaining Mo and $\mathrm{V}$. The sodium aluminate is recovered from the liquor as very pure $\mathrm{Al}(\mathrm{OH})_{3}$. Mo can be recovered in the form of molybdic acid using a process based on treating the spent catalyst with 1 to 3 parts of $\mathrm{H}_{2} \mathrm{SO}_{4}$, per 1 part of the spent catalyst [8]. The process employs a sulphide atmosphere between 298 and $473 \mathrm{~K}$, and pressure of 1 to 35 atm.

\section{Materials and Methods}

\subsection{Samples}

Spent catalyst was obtained from the residue gasoil hydrodesulfurization unit of PEMEX. The particle size is between 1.5 and $7.3 \mathrm{~mm}$, and it contains nickel and molybdenum as active constituents. Used reagents like $\mathrm{H}_{2} \mathrm{O}$, $\mathrm{HCl}$, and $\mathrm{NaOH}$, used were of AR grade. The reaction between the spent catalyst, the caustic soda, and hydrochloric acid was performed in a $250 \mathrm{~mL}$ round bottom flask.

\subsection{Analysis Methods}

The chemical composition the catalyst was determined by Infrared spectroscopy, X-ray fluorescence, scanning electron microscopy, and X-ray diffraction.

\subsection{Calcination Process}

In each experiment, twenty gram of spent catalyst was calcinated. The calcination processes materials at temperatures up to $450^{\circ} \mathrm{C}$. The reactions available include removal of sulfur, carbon, and oxidizing of vanadium sulfide [9].

Fourteen grams of spent catalyst calcinated was added at a time, to the agitated caustic soda solution $(50 \mathrm{~mL})$ of the required concentration, time, and temperature. The leached solution was filtered. Vanadium and molybdenum were dissolved into sodium vanadate and sodium molybdate and $\mathrm{pH}$ was adjusted to 3.0 - 3.5 by the addition of dilute hydrochloric acid. Vanadium and molybdenum precipitated as vanadium pentoxide and molybdenum trioxide. The nickel aluminate was obtained from the residue left the after removal of vanadium and molybdenum. Afterwards, the samples were analyzed for the determination of metals content, using scanning electron microscope (SEM) analysis in conjunction with energy dispersive X-ray analysis. The detailed procedure is presented in Figure 1.

\section{Results and Discussion}

\subsection{Analysis of the Catalyst}

Table 1 shows the chemical analysis data for the spent catalyst used.

The compound aluminum carbide is the most abundant. According to literature [10] materials with a matrix of aluminum, which interacts with carbon containing compounds, reacts at high temperatures forming $\mathrm{Al}_{4} \mathrm{C}_{3}$. Hydrocarbons and elemental sulfur make up about 30\% from the total sample, and correspond to volatile com-

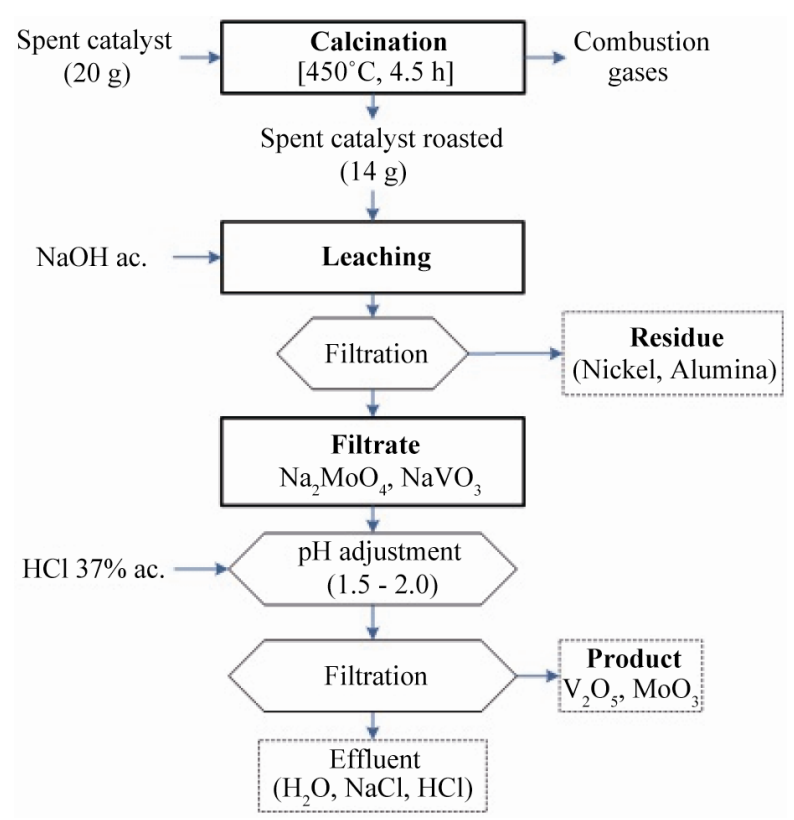

Figure 1. Schematic diagram for the extraction of Molybdenum and vanadium from HDS spent catalyst. 
pounds. The addition of vanadium compounds are equal to the fifth part of the composition. Molybdenum is in the new catalyst as sulfur, but given the conditions of operation in which it is handled, it is molybdenum trioxide. Most of the $\gamma-\mathrm{Al}_{2} \mathrm{O}_{3}$ has reacted with a) the steam process $\left(\mathrm{Al}_{4} \mathrm{C}_{3}\right)$, and $\left.\mathrm{b}\right)$ with the same components from the catalyst $\left(\mathrm{NiAlO}_{4}\right)$.

\subsection{Effect of Time on Extraction of Vanadium and Molybdenum}

A spent catalyst with $6 \%$ of caustic soda, during a period of time from 1 to $8 \mathrm{~h}$, at a constant temperature of $25^{\circ} \mathrm{C}$ was carried out (Figure 2). The time has a significant effect on the dissolution of molybdenum and vanadium oxides. After $4 \mathrm{~h}$ of leaching time, $67.3 \% \mathrm{~V}$ and $57.8 \%$ Mo were extracted. A further increase of time produces a decrease in the recovery which may be attributed to the gradual decrease of surface area of the reactant. Thus, an optimum time of $4 \mathrm{~h}$ was chosen.

\subsection{Effect of Caustic Soda Concentration on Extraction of Vanadium and Molybdenum}

The effect of caustic soda concentration on leaching of spent HDS catalyst was studied using different concentrations in the range $6 \%-20 \%$ at a constant temperature equal to $25^{\circ} \mathrm{C}$, the results are shown in Figure 3. Figure 3 reveals that at $20 \mathrm{wt} \%$ of caustic soda content in the feed mixture, molybdenum recovery reaches $91.0 \%$ and about $97 \%$ of the $\mathrm{V}$ present in the spent catalyst was extracted. An increase in caustic soda content produces a proportional variation in Mo and $\mathrm{V}$ recovery; Aluminum also has been extracted like $\mathrm{Al}(\mathrm{OH})_{3}$, due to at high soda concentrations cause a greater probability of collision between the molecules. Thus, $20 \mathrm{wt} \%$ caustic soda addition is considered to be the optimum.

Table 1. Chemical analysis data for the spent catalyst.

\begin{tabular}{ccccccccccc}
\hline Compound & $\mathrm{Al}_{4} \mathrm{C}_{3}$ & $\mathrm{HC}$ 's & $\mathrm{V}_{2} \mathrm{O}_{5}$ & $\mathrm{~S}$ & $\mathrm{MoO}_{3}$ & $\mathrm{NiAlO}_{4}$ & $\mathrm{~V}_{2} \mathrm{~S}_{5}$ & $\gamma-\mathrm{Al}_{2} \mathrm{O}_{3}$ & $\mathrm{Others}_{2}$ \\
\hline$\% \mathrm{w}$ & 28.44 & 20.73 & 15.48 & 9.64 & 8.45 & 8.35 & 4.64 & 3.28 \\
\hline
\end{tabular}

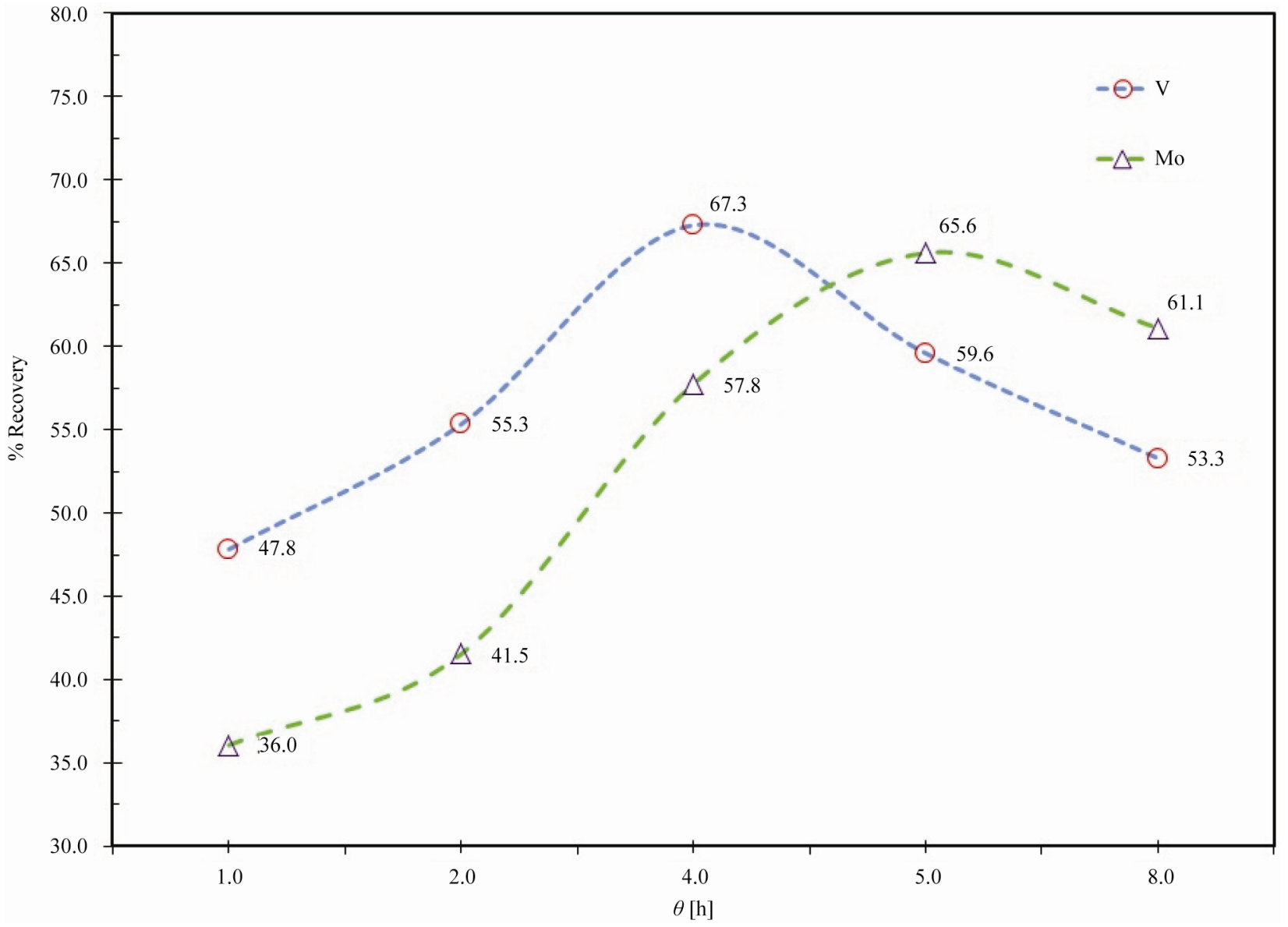

Figure 2. Effect of time on extraction of vanadium and molybdenum. 


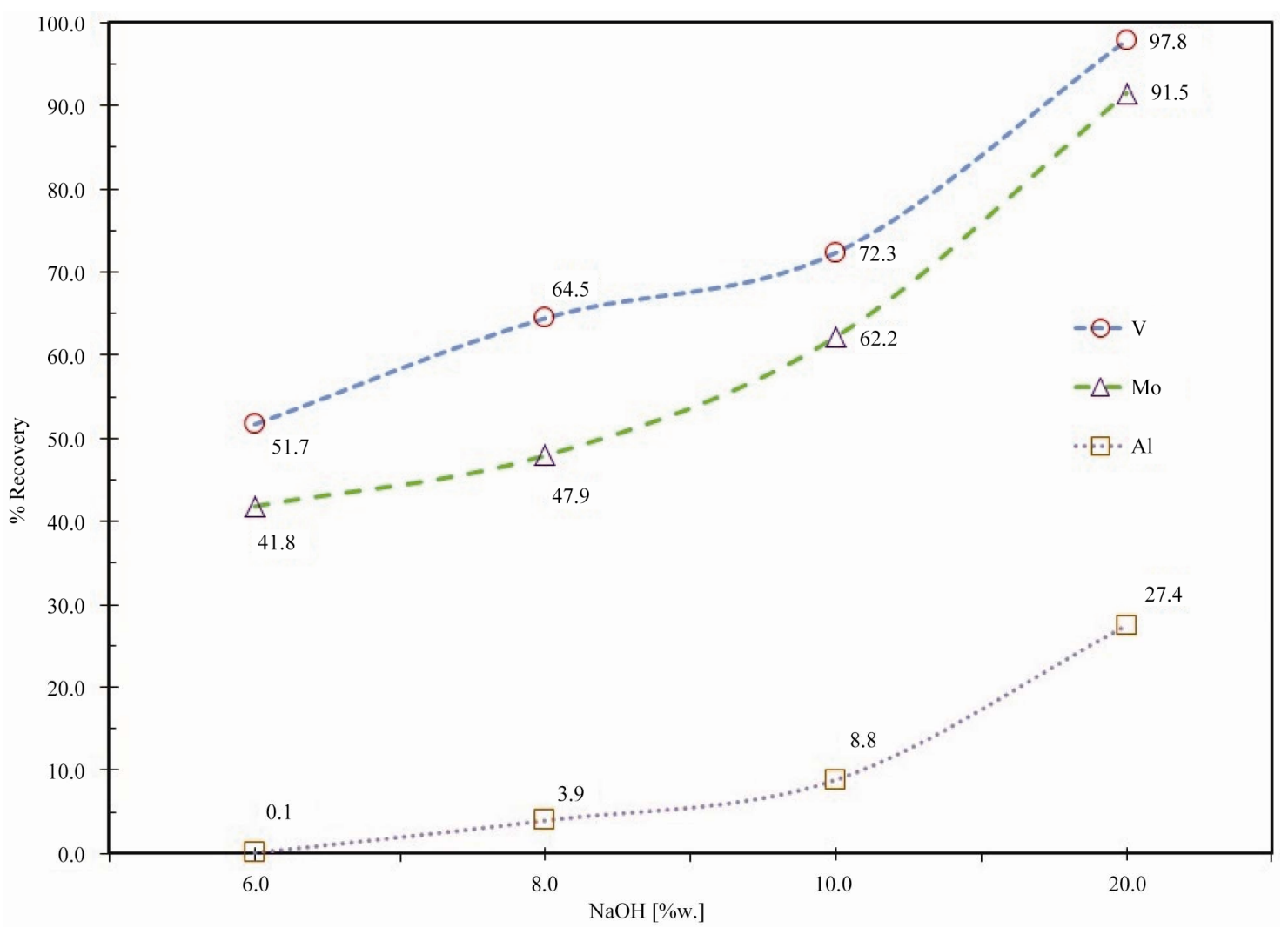

Figure 3. Effect of caustic soda concentration on extraction of vanadium and molybdenum.

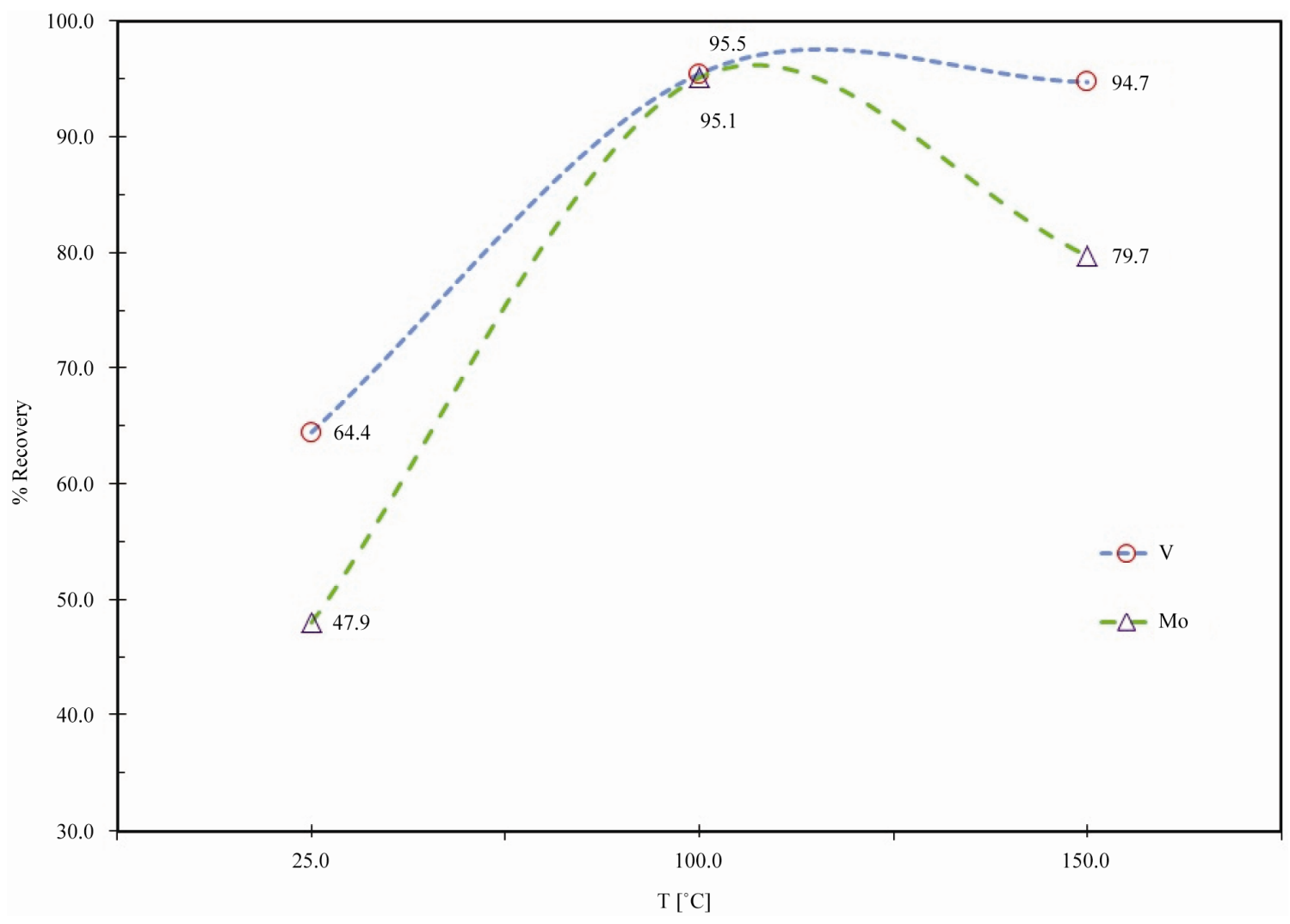

Figure 4. Effect of temperature on extraction of vanadium and molybdenum. 


\subsection{Effect of Temperature on Extraction of Vanadium and Molybdenum}

The effect of reaction temperature on $\mathrm{V}$ and Mo extraction is plotted in Figure $\mathbf{4}$ for spent catalyst of $2 \mathrm{~h}$ time period and $8 \%$ caustic concentration, within a temperature range of $25^{\circ} \mathrm{C}-150^{\circ} \mathrm{C}$.

Figure 4 reveals that temperature of $100^{\circ} \mathrm{C}$ seems to be sufficient enough to recover about $95.1 \%$ and $95.5 \%$ of the $\mathrm{V}$ and Mo present in the spent catalyst. Since the entire reaction was completed within $100^{\circ} \mathrm{C}$, further increase in this time does not affect the molybdenum or vanadium recovery.

\section{Conclusions}

The investigation performed revealed that molybdenum and vanadium spent catalyst generated from hydro-refining plants can be a secondary source of Mo and V.

Leaching with caustic soda is efficient for low concentrations of plant catalyst and allows recovery of molybdenum as trioxide, and vanadium as pentoxide. Under selected experimental conditions, i.e. leaching at room temperature the spent catalyst needs to be leached with $20 \% \mathrm{NaOH}$ solution to form soluble vanadium and molybdenum compounds and it is easy to recovery of oxides. wt $\%$ caustic soda for 60 min up to $95 \%$ molybdenum and vanadium are extracted from a hydro-refining spent catalyst.

The rate of extraction of $\mathrm{V}$ and Mo was found maximum at temperature $100^{\circ} \mathrm{C}$ further increase temperature no adverse effect on oxides extraction.

The residue left after recovery of vanadium and molybdenum leaching, contains $\mathrm{Ni}$ as nickel aluminate.

\section{REFERENCES}

[1] E. Furimsky, "Spent Refinery Catalysts: Environmental,
Safety and Utilization,” Catalysis Today, Vol. 30, No. 4, 1996, pp. 223-286. doi:10.1016/0920-5861(96)00094-6

[2] A. G. Case and E. Wiewiorowski, "Ten Years of Catalyst Recycling: A Step to the Future,” 3rd International Symposium on Recycling of Metals and Engineered Materials, Point Clear, 12-15 November 1995, pp. 449-466.

[3] K. Inoue, H. Tsuyama, K. Yoshizuka and P. Zhang, "Extraction and Selective Stripping of Molybdenum(VI) and Vanadium(IV) from Sulfuric Acid Solution Containing Aluminum(III), Cobalt(II), Nickel(II) and Iron(III) by LIX 63 in Exxsol D80,” Hyrdometallurgy, Vol. 41, No. 1, 1996, pp. 45-53. doi:10.1016/0304-386X(95)00015-9

[4] C. L. Van Deelen, "Method for Extracting Metals from Catalyst on the Basis of $\mathrm{Al}_{2} \mathrm{O}_{3}$," European Patent No. WO 95014, 1994.

[5] J. Mining and S. Toda, "Alkaline Roasting of Spent Catalyst Containing Molybdenum and Vanadium,” Journal of Mineral and Materials Processing Institute of Japan, Vol. 105, No. 3, 1989, pp. 261-264.

[6] R. K. Biswas, M. Taniguchi and M. Wakihara, "Recovery of Vanadium and Molybdenum from Heavy Oil Desulphurization Waste Catalyst," Hydrometallurgy, Vol. 14, No. 2, 1985, pp. 219-230. doi:10.1016/0304-386X(85)90034-9

[7] R. W. Goerlich, R. C. Kunzelman, C. A. Vuitel and J. G. Welch, "Catalyst Disposal an Environmentally Sound Solution," Symposium on Refinery Waste Cleanup, New Orleans, 10 August-4 September 1987, pp. 747-750.

[8] D. E. Hyatt, "Value Recovery from Spent Alumina-Base Catalyst," US Patent No. 4657745, 1987.

[9] V. F. Bukhanevich and S. V. Radzikovskaya, "Vanadium Sesquisulfide and Its Properties," Powder Metallurgy and Metal Ceramics, Vol. 6, No. 2, 1967, pp. 91-92. doi:10.1007/BF00775636

[10] M. Campo, J. Rams and A. Ureña, "Determination by Nanoindentation of the Interfacial Mechanical Properties in Aluminum Matrix Composites Reinforced with Silica Coated Sic Particles,” Boletín de la Sociedad Española de Ceramica y Vidrio, Vol. 44, 2005, pp. 270-277. 